\title{
Effects of plant diversity on soil erosion for different vegetation patterns
}

\author{
Jian Hou ${ }^{\mathrm{a}, *}$, Huiqing Wang ${ }^{\mathrm{b}}$, Bojie $\mathrm{Fu}^{\mathrm{c}}$, Linhai Zhu ${ }^{\mathrm{c}}$, Yafeng Wang ${ }^{\mathrm{c}}$, Zongshang $\mathrm{Li}^{\mathrm{c}}$ \\ a School of Soil and Water Conservation, Beijing Forestry University, 100083 Beijing, PR China \\ ${ }^{\mathrm{b}}$ Hulun Buir Bureau of Meteorology, Hailaer 021000, PR China \\ c State Key Laboratory of Urban and Regional Ecology, Research Center for Eco-Environmental Sciences, Chinese Academy of Sciences, P. O. Box 2871, Beijing 100085, PR China
}

\section{A R T I C L E I N F O}

\section{Article history:}

Received 18 September 2015

Received in revised form 2 August 2016

Accepted 11 August 2016

Available online 20 August 2016

\section{Keywords:}

Soil ${ }^{137}$ Cs

Vegetation coverage

Vegetation pattern

Plant distribution

\begin{abstract}
A B S T R A C T
Vegetation effectively prevents soil erosion. However the relationship between plant diversity and soil erosion remains ambiguous under various environmental conditions. To explore the role that plant diversity plays in soil erosion, this study was conducted in the Three-River-Source region, located in the hinterlands of the Qinghai-Tibet Plateau, China. After examining 99 plots within the study area, and analyzing the soil ${ }^{137} \mathrm{Cs}$ inventory within the plots, we found that with a greater number of plants distributed within an aggregation pattern, there was greater interception of the soil particles by the vegetation patch. This phenomenon results in a more developed vegetation patch that can support greater vegetation coverage and higher plant diversity than it previously could. Although a positive correlation exists between plant diversity and vegetation coverage, the relationship between the extent of soil erosion and plant diversity is modulated by the vegetation pattern. When plants are distributed in a relatively homogeneous pattern, vegetation coverage decreases with increasing plant diversity, which leads to increased soil erosion. When plants are distributed between a homogenous and a heterogeneous pattern, no relationship is found between plant diversity and soil erosion. With a heterogeneous plant distribution, vegetation coverage increases with plant diversity, and soil erosion is inhibited under such conditions.
\end{abstract}

@ 2016 Elsevier B.V. All rights reserved.

\section{Introduction}

Soil erosion is an important ecological problem that has garnered increasing attention (Boardman, 2006). Because vegetation cover can effectively prevent soil erosion, more research on the relationship between vegetation and soil erosion has recently been conducted. Nearly all of these studies have found a negative relationship between vegetation coverage (VC) and soil erosion (Marques et al., 2007; Zhou et al., 2008). The negative correlation usually extends from a linear (Greene et al., 1994) to an exponential (Marston, 1952) correlation. Similarly, because of the important role that vegetation patterns play in the progression of soil erosion, an increasing number of studies have been conducted to examine the relationship between vegetation patterns and soil erosion (Cerda, 1997; Saco et al., 2007). Most studies have found that different vegetation patterns may combine with different soil erosion processes, even with similar VCs (Boix-Fayos et al., 2007). After conducting a study in northeastern Australia, Ludwig et al. (2007) suggested that a greater intensity of soil erosion is usually more associated with heterogeneous vegetation patterns rather than homogeneous vegetation patterns. In addition, the relationship between plant diversity

\footnotetext{
* Corresponding author at: School of Soil and Water Conservation, Beijing Forestry University, Beijing 100083, PR China.

E-mail address: houjian@bjfu.edu.cn (J. Hou).
}

and soil erosion can be affected by the vegetation pattern (Bautista et al., 2007). It has been suggested that similar vegetation patterns can be better conditions for determining the relationship between plant diversity and soil erosion than areas with different vegetation patterns (Hou et al., 2014).

Aside from the vegetation pattern, several other factors, such as precipitation conditions, affect the relationship between plant diversity and soil erosion. This relationship is thus ambiguous under different environmental conditions (Bautista et al., 2007). For example, a positive correlation between plant diversity and soil erosion has frequently been observed; however, a negative correlation has also been found (Turnbull et al., 2008). After conducting research in the Netherlands, Martin et al. (2010) found that different vegetation conditions give rise to different correlations between plant diversity and soil erosion. Whether the correlation between plant diversity and soil erosion is positive or negative largely depends on the local environment.

The relationship between these conditions is complex. With respect to plant diversity, discussing the relationship between plant diversity and soil erosion is perhaps not as valuable as discussing the relationship between plant functional diversity and soil erosion (Cadotte et al., 2011). Because plants have specific functional traits, such as root diameter, root tensile strength, and plant height, a plant's effects on soil erosion can be directly expressed as the effects of the plant's functional traits on soil erosion. Indeed, plant functional traits have been found to significantly affect soil erosion (Burylo et al., 2012; Pohl et al., 2009). The effect of vegetation 
diversity on soil erosion is actually the result of the effects of plant functional diversity on soil erosion. Nonetheless, studying the relationship between plant functional diversity and soil erosion is not unproblematic. First, the functional traits within a community must be categorized. Second, each functional trait of each plant species within a community must be quantified to study the relationship between only one type of erosion and plant functional diversity. More importantly, plant functional traits change over time and cannot be precisely quantified.

It is neither easy nor effective to study plant functional traits. However, studying plant functional types can be used to overcome these shortcomings. The plant functional type refers to a vegetation group that consists of plants with similar functional traits that respond in a similar pattern to an environmental disturbance (Navarro et al., 2006). Relying on plant functional types is an effective means of studying plant diversity and soil erosion from the plot (Anderson and Hoffman, 2011 ) to the landscape scale (Navarro et al., 2006); however, certain details are lost in studies that focus on plant functional traits. Generally, plant functional traits increase with plant diversity in a community. Thus, studying the relationship between plant functional diversity and erosion can serve as a good substitute for studying the relationship between plant diversity and erosion and potentially reveal the relationship between each functional trait and soil erosion.

Soil erosion can be expressed by different erosion types, such as splash, runoff, and windy erosion, among others (Boardman, 2006). Different erosion processes and steps have different traits, which can be affected by different plant functional traits (Zhu et al., 2015). Soil erosion types are thus meaningful for studying the relationship between soil erosion and plant diversity or plant functional diversity. In this study, the results of soil erosion over many years were monitored using an environmental tracer. The relationship between the results and plant diversity was studied.

Recently, soil ${ }^{137} \mathrm{Cs}$, an environmental tracer, has begun to be used more frequently to evaluate soil erosion (Fu et al., 2009; Zhang et al., 2003). The theory of this method can be described as follows. From the 1950s to the 1970s, there was global fallout from bomb-derived radiocesium. When ${ }^{137} \mathrm{Cs}$ arrives at the ground surface, it is strongly and rapidly adsorbed by soil particles. When these soil particles move, ${ }^{137} \mathrm{Cs}$ accompanies them. Consequently, it is possible to evaluate whether a site is experiencing soil loss or accumulation by monitoring the spatial pattern of ${ }^{137} \mathrm{Cs}$ (Porto et al., 2001). A site with a greater soil ${ }^{137} \mathrm{Cs}$ inventory indicates that more sediment has accumulated at this site. However, a lower ${ }^{137} \mathrm{Cs}$ inventory in a site indicates that more sediment has been transported away from the site. Monitoring the results of the soil ${ }^{137} \mathrm{Cs}$ inventory at a site can be used to quantitatively evaluate the results of soil erosion that has taken place for nearly 60 years (from the 1950s-1970s until the present) at this site.

Several conversion models can be used to estimate soil erosion by measuring the soil ${ }^{137}$ Cs inventory (Parsons and Foster, 2011), including, for example, the mass balance model and the simplified mass balance model (Fu et al., 2009). Different models have different parameters and differ in their underlying assumptions (Porto et al., 2001). In this study, conversion models were not used to estimate the extent of soil erosion, to prevent mistakes from arising as a result of complex model conversion. Instead, soil erosion within different plots was compared by comparing the soil ${ }^{137} \mathrm{Cs}$ inventory within different plots.

This research was conducted in the Three-River-Source region (the headwaters of the Yellow River, the Yangtze River, and the Lancang River), which is located in the hinterlands of the Qinghai-Tibet Plateau. Because this region is the major area of origin of the main rivers in Asia, the ecological health of this region may be closely related to sustainable development throughout most of Asia (Fassnacht et al., 2015). Due to global warming and human activities, the ecosystem in this region has experienced continuous degradation, an issue that has recently begun to attract more attention (Harris, 2010; Lehnert et al., 2014). This study was conducted to provide a theoretical basis for preventing soil erosion, a major contributing factor involved in land degradation. The main aim of this study is to explore the impact of plant diversity on soil erosion.

\section{Materials and methods}

\subsection{Study site}

This study was conducted in the Three-River-Source region of the Qinghai-Tibet Plateau, China $\left(31^{\circ} 39^{\prime}-36^{\circ} 12^{\prime} \mathrm{N}, 89^{\circ} 45^{\prime}-102^{\circ} 23^{\prime} \mathrm{E}\right)$ (Fig. 1). Because this region is the source of three major rivers in China, it is known as "the water tower of China". The region is located in the hinterlands of the Qinghai-Tibet Plateau and has a total area of approximately $302,500 \mathrm{~km}^{2}$, which amounts to nearly $12 \%$ of the Qinghai-Tibet Plateau. The altitude ranges from 2610 to $6950 \mathrm{~m}$. The study area has a continental monsoon climate typical to the plateau. The annual mean temperature in this area ranges from $5.38{ }^{\circ} \mathrm{C}$ to $4.14{ }^{\circ} \mathrm{C}$, and the annual precipitation ranges from $262.2 \mathrm{~mm}$ to $772.8 \mathrm{~mm}$ (Yi et al., 2013). Monthly mean precipitation of the study area over 40 recent years (1969-2009) are presented in Fig. 2 (Li et al., 2009). There are approximately 0.12 hundred million $\mathrm{hm}^{2}$ of moderately or seriously degraded grassland in this region; such ecosystem degradation has garnered increased attention worldwide (Liu et al., 2008).

\subsection{Field investigations}

In July 2014, we investigated 99 plots throughout the Three River Headwaters region. The condition of the plots selected was: 1) flat terrain; 2) zonal vegetation; 3 ) no anthropogenic disturbance; 4) no gravel cover, and 5) little or no moss cover. Each plot was 0.5 by $0.5 \mathrm{~m}^{2}$. Within each plot, we recorded VC, species number, mean height, and the number of individuals of each species directly. In addition, the plots were photographed with a digital camera held $1 \mathrm{~m}$ above the ground. A photo was taken of every plot to analyze the vegetation patterns (Fig. 1). Because there were few liverworts, mosses, and stones within the plots selected, these were not recorded. The distribution of soil in vertical sections according to the ${ }^{137} \mathrm{Cs}$ inventory shows little inventory at depths $>40 \mathrm{~cm}$. Within $40 \mathrm{~cm}$, soil erosion can be analyzed satisfactorily by monitoring the ${ }^{137} \mathrm{Cs}$ inventory. Therefore, soil samples were collected at 0-40 cm depth below the group, and the internal diameter of the soil auger was $0.028 \mathrm{~m}$. Within each plot, three randomly placed soil samples were collected, and then mixed together in one sample. The soil ${ }^{137} \mathrm{Cs}$ inventory of each sample was analyzed in the laboratory.

\subsection{Laboratory tests}

Soil samples were air-dried in a hood, and sieved using a 2-mm screen. Next, a HPGe co-axial detector coupled to a multichannel analyzer was used to determine the soil ${ }^{137} \mathrm{Cs}$ inventory for each sample. The ${ }^{137} \mathrm{Cs}$ activity was detected at $662 \mathrm{keV}$, with a counting time of approximately $30,000 \mathrm{~s}$ for the detection. The results provided by this test were at least $90 \%$ reliable at a $95 \%$ confidence level. Calculations of the soil ${ }^{137} \mathrm{Cs}$ inventory was referenced to standards (Fu et al., 2009).

\subsection{Index calculations}

As a common index in ecology, Shannon's diversity index (SHDI) was used to estimate plant diversity (Riis and Hawes, 2002). This index was calculated using the following formula:

Shannon's diversity index $=-\sum_{i=1}^{\mathrm{m}}\left(P_{i} \ln P_{i}\right)$

$P_{i}$ is the proportion of the number of all plants in a plot occupied by the number of plant species $i$. $m$ denotes the number of species in a plot. 


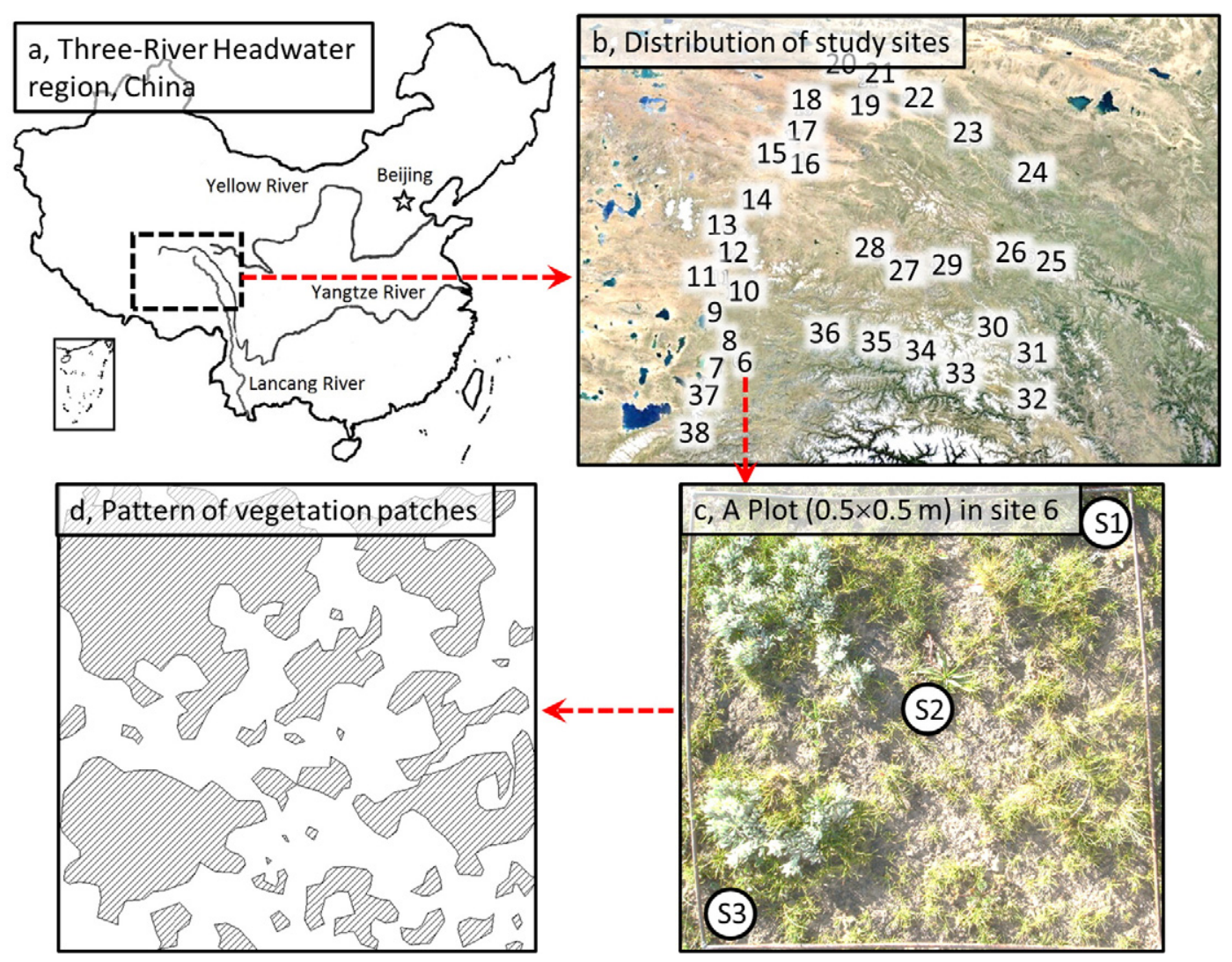

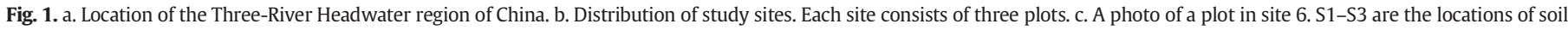
samples in the plot. $d$. The raster graph transformed from the plot for site 6 . This raster graph can be used to analyze the aggregation index.

Landscape shape index (LSI) was used to evaluate the vegetation pattern. This index value decreases as the pattern becomes more aggregated. This index can be presented as follows:

Landscape shape index $=\frac{0.25 \times \mathrm{E}}{\sqrt{\mathrm{A}}}$

where $\mathrm{E}=$ total length $(\mathrm{m})$ of edge of patches in a landscape (raster graph in this research); $\mathrm{A}=$ total patches area $\left(\mathrm{m}^{2}\right)$. $\mathrm{LSI}=1$ when the landscape consists of a single square patch; LSI increases without limit as landscape shape becomes more irregular or as the length of an edge within the landscape increases. Plot photos were used to produce

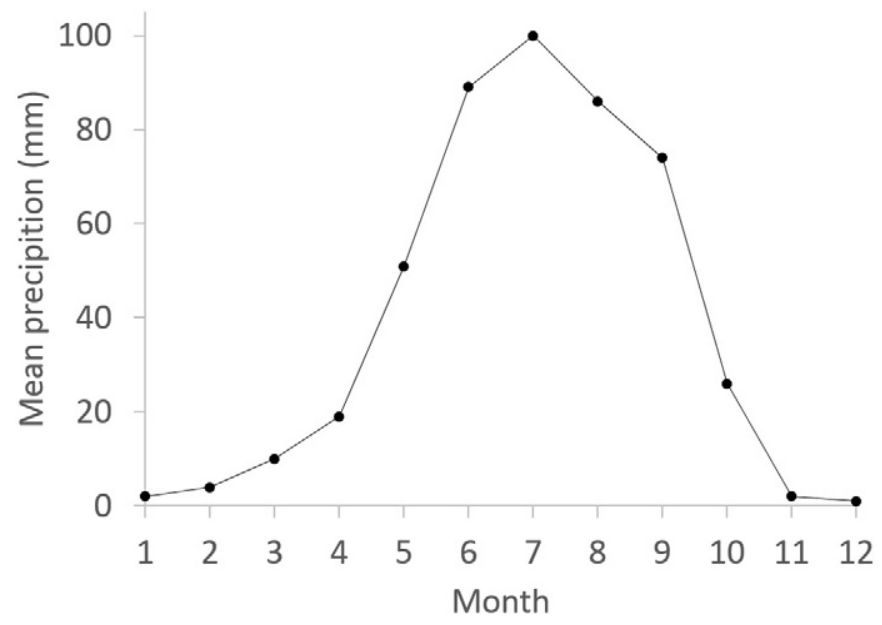

Fig. 2. Monthly mean precipitation of the study area from 1969 to 2009 (Li et al., 2009). the raster graph, and the vegetation pattern within each plot can be identified via an index calculation with software Fragstats v4.2.1.

\subsection{Data analysis}

First, the Shapiro-Wilk normality test was used to check for the normal distribution of data prior to analysis. The VC data were also transformed to fit the normal distribution. The transformational formulation is as follows:

$\operatorname{data}_{2}=\sin ^{-1} \sqrt{\text { data }_{1}}$

where $d a t a_{1}$ denotes the origin data, whereas data $_{2}$ encompasses the data that have been transformed. After transformation, the data in each dataset represent approximately the normal distribution (Shapiro-Wilk normality test: $p<0.05$ ).

Second, the coefficients of Pearson's correlation tests were calculated for every soil ${ }^{137} \mathrm{Cs}$ inventory, and for the LSI and Shannon's diversity index for all plots, to evaluate the relationship between them.

Third, to demonstrate the relationship between plant diversity and soil erosion under similar vegetation patterns, plots were arranged in ascending order according to the value of LSI. Then, all 99 plots were divided into nine groups of 11 plots each. For example, plots 1 to 11 were grouped into group 1, plots 12 through 22 were grouped into group 2, and so on, according to the order of ascending LSI value. Thus, the plots within group 1 hold minimum LSI values, and the plots within group 9 hold maximum LSI values. Using this method, the vegetation pattern will be more similar within a group than within all plots. The results for each group and the characteristics of the plants and soil in each group are presented in Table 1. Within each group, Pearson's correlation tests were conducted between plant diversity and soil ${ }^{137} \mathrm{Cs}$ inventory, and between plant diversity and VC. 
Table 1

Characteristics of the plants and soil in each group.

\begin{tabular}{lllll}
\hline Group & $\begin{array}{l}\text { Ranges of } \\
\text { LSI }\end{array}$ & $\begin{array}{l}\text { Soil }{ }^{137} \text { Cs inventory } \\
\left(\mathrm{Bq} / \mathrm{m}^{2}\right)\end{array}$ & $\begin{array}{l}\text { Vegetation } \\
\text { coverage }(\%)\end{array}$ & $\begin{array}{l}\text { Species } \\
\text { richness }\end{array}$ \\
\hline 1 & $1.82-3.08$ & $787.2 \pm 506.2$ & $51.4 \pm 41.7$ & $4.29 \pm 2.63$ \\
2 & $3.16-3.75$ & $1600.7 \pm 1632.6$ & $53.3 \pm 38.6$ & $4.71 \pm 3.66$ \\
3 & $4.11-5.11$ & $847.3 \pm 579.0$ & $35.5 \pm 40.2$ & $4.75 \pm 4.09$ \\
4 & $5.16-5.86$ & $823.2 \pm 466.3$ & $34.5 \pm 32.3$ & $4.50 \pm 2.21$ \\
5 & $5.99-6.71$ & $1965.4 \pm 1926.4$ & $41.0 \pm 24.7$ & $4.13 \pm 2.95$ \\
6 & $6.76-6.88$ & $1474.3 \pm 763.2$ & $43.4 \pm 44.4$ & $4.63 \pm 1.76$ \\
7 & $6.88-7.59$ & $834.2 \pm 654.1$ & $35.7 \pm 27.9$ & $5.25 \pm 2.39$ \\
8 & $7.80-8.99$ & $1071.2 \pm 517.3$ & $40.7 \pm 20.1$ & $4.88 \pm 3.02$ \\
9 & $9.20-11.42$ & $945.8 \pm 819.9$ & $40.4 \pm 24.8$ & $4.33 \pm 1.17$ \\
\hline
\end{tabular}

Note: The values are presented as the mean \pm standard deviation. LSI: landscape shape index.

A raster graph was produced by ArcGis10.3. LSI was conducted using Fragstats3.3. SHDI was calculated with the R-3.2.2. The Shapiro-Wilk normality test, and Pearson's correlation test were calculated using SPSS17.0.

\section{Results}

Accord to the results of Shao et al. (2011), the background value of the soil ${ }^{137} \mathrm{Cs}$ inventory in the Three Rivers Source region is approximately $2000 \mathrm{~Bq} / \mathrm{m}^{2}$. This value can be used to determine whether a plot experienced erosion or deposition. We found that plots 14-2, 182, 20-1, 21-3, 22-1, 22-2, 24-3, 28-1, 29-3, and 36-1 experienced soil deposition, while the other plots experienced erosion (Fig. 3 ).

The results of Pearson's correlation tests for all plots indicate that significant positive correlations exist between the soil ${ }^{137} \mathrm{Cs}$ inventory and VC, aside from the correlation between soil ${ }^{137} \mathrm{Cs}$ inventory and SHDI (Table 2).

The results of Pearson's correlation tests for the plots within each group demonstrate that the correlations between SHDI and soil ${ }^{137} \mathrm{Cs}$ inventory or VC differ among different groups (Fig. 4). Namely, there are two similar trends in which the Pearson's correlation coefficients $(r)$ for the two pairs change from positive to negative from groups 1 through 9. For example, within group 1, the correlation between SHDI and VC is a significant positive correlation at a level of 0.01 , and the correlation between SHDI and the soil ${ }^{137}$ Cs inventory is a significant

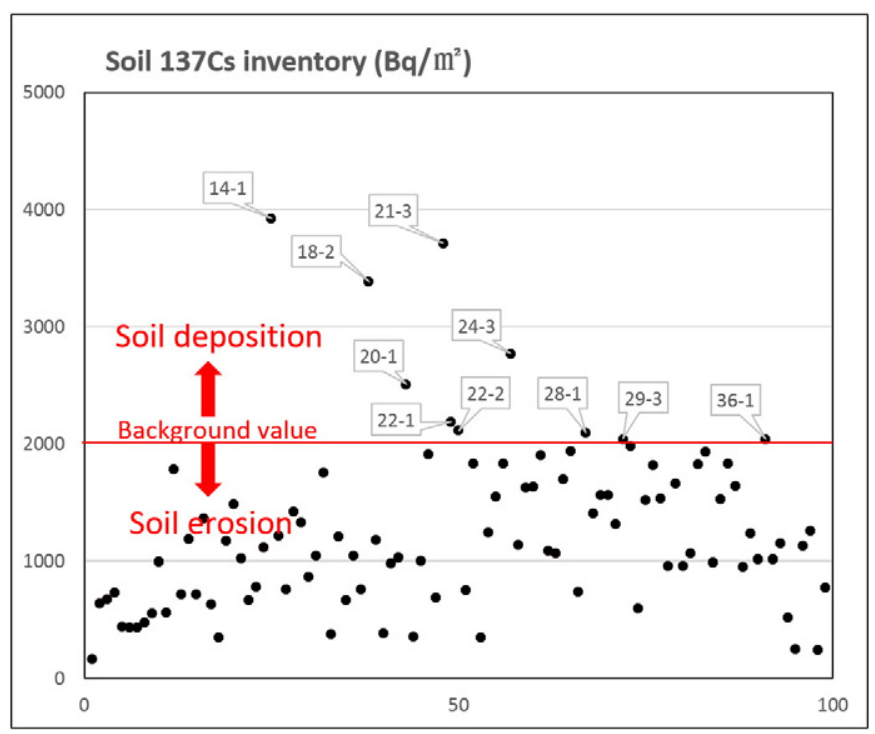

Fig. 3. The background value of soil ${ }^{137} \mathrm{Cs}$ inventory (Shao et al., 2011) was used to determine whether a plot experienced erosion or deposition. We determined that plots with values of soil ${ }^{137} \mathrm{Cs}$ inventory higher than the background value experienced deposition, while those with values of soil ${ }^{137} \mathrm{Cs}$ inventory below the background value experienced erosion.
Table 2

Results of Pearson's correlation test for all plots.

\begin{tabular}{llll}
\hline & Soil ${ }^{137}$ Cs inventory & VC & SHDI \\
\hline Soil ${ }^{137}$ Cs inventory & 1 & & \\
VC & $0.347^{* *}$ & 1 & \\
SHDI & 0.193 & $0.609^{* *}$ & 1 \\
LSI & 0.030 & -0.315 & 0.002
\end{tabular}

Parameter definitions: LSI: landscape shape index; VC, vegetation coverage; SHDI, Shannon's diversity index.

** Significant correlation at a level of 0.01 .

positive correlation at a level of 0.01 . From groups 2 to 8 , most correlation coefficients for SHDI and the soil ${ }^{137} \mathrm{Cs}$ inventory or VC are not significant. However changing trends among the coefficients are from a positive to negative correlation. Within group 9, the correlation coefficients for SHDI and the soil ${ }^{137} \mathrm{Cs}$ inventory or VC are significant negative correlations at a level of 0.01 (Fig. 4).

\section{Discussion}

There is a positive correlation between VC and the soil ${ }^{137} \mathrm{Cs}$ inventory/SHDI for all plots (Table 2). Because of the effects of vegetation coverage on soil erosion, with increases in VC, soil particles, with soil ${ }^{137} \mathrm{Cs}$ inventory and nutrients, can be increasingly intercepted by vegetation patches. This results in more developed vegetation patches, which have greater plant diversity. Thus, a positive correlation exists between SHDI and VC for all plots (Table 2).

With respect to SHDI, although there is a positive correlation between SHDI and VC for all plots, there is no relationship between SHDI and the soil ${ }^{137} \mathrm{Cs}$ inventory (Table 2). It has thus been suggested that the relationship between the soil ${ }^{137} \mathrm{Cs}$ inventory and species diversity (SHDI) can be modulated by the vegetation pattern (LSI) (Bautista et al., 2007). To reveal whether similar vegetation patterns can present the relationship between plant diversity (SHDI) and the extent of soil erosion (soil ${ }^{137} \mathrm{Cs}$ inventory) better than different patterns (Hou et al., 2014), these plots were divided into nine groups. There are more similar vegetation patterns within a group than between groups.

The relationship between plant diversity and soil erosion can be shown for different vegetation patterns, ranging from homogeneous to heterogeneous.

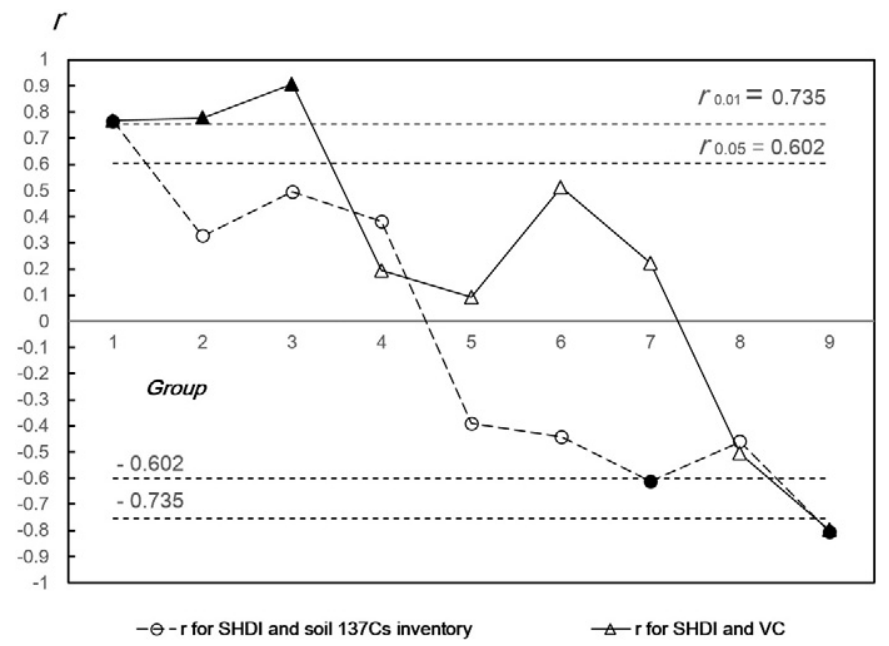

Fig. 4. The results of Pearson's correlation tests for the plots within groups 1-9. $r$ refers to Pearson's correlation coefficients. The x-axis identifies the group. The y-axis describes the $r$ value. An $r$ value higher than 0.735 , indicates a significant positive correlation at a level of 0.01 . Meanwhile, an $r$ value lower than -0.735 indicates a significant negative correlation at a level of 0.01 . The same holds true for the $r$ value at a level of 0.05 . $r$ values of significant correlation are marked with solid symbols. 
(1) Under conditions of a relatively homogeneous vegetation pattern (Group 9, Table 1; Table 3; Fig. 4): A negative correlation is found between plant diversity and coverage, and between plant diversity and the amount of soil accumulation (Fig. 4). This can be explained in two ways: one suggestion is that high performing monocultures may be more effective in preventing soil erosion than adding lower performing species in the homogeneous pattern. Thus, as plant diversity increases, soil accumulation decreases. The other suggests that because of the relatively homogeneous plant distribution (Table 1 ), the vegetation patches under this condition are not developed enough to intercept rainfall, runoff, and accumulate soil resources. It is thus suggested that the distribution of soil resources adheres to a homogeneous pattern. Due to various plant species with different resource requirements occupying different niches, different plant species tend to distribute closely, while the same plant species with similar niches tend to distribute far away from one another because of competition (Anthwal et al., 2008). As a result, with increasing plant diversity, more and more plants distribute closely, and plant canopies increasingly overlap, while VC contracts. Due to vegetation coverage's inhibiting effect on soil erosion, soil loss increases with decreased coverage.

(2) Under conditions in which the vegetation shifts between a homogeneous and heterogeneous distribution (Groups 2-8, Table 1 ): It has been found that the correlation between plant diversity and VC, as well as the correlation between plant diversity and soil accumulation, has generally been found not to be significant (Fig. 4). Under these conditions, plant distribution is suggested to develop from a homogeneous to a heterogeneous distribution. Thus, there is generally no straightforward correlation between plant diversity and vegetation coverage or soil loss.

(3) Under conditions of a relatively heterogeneous vegetation pattern (Group 1, Table 1): A positive correlation between plant diversity and VC, and between plant diversity and the amount of soil accumulation (Fig. 4) has been found. Due to the relatively heterogeneous distribution of the plants, the vegetation patches were developed sufficiently to intercept rainfall, runoff, and soil resources. These can reduce splash erosion, prevent soil loss within the patches, and intercept external runoff. With increasing plant diversity, more and more habitats are occupied by different plant species with various niches within the developed vegetation patches. This circumstance leads to increasing VC and more developed patches that can intercept more soil particles.

Table 3

Average coverage of individual species in all plots.

\begin{tabular}{llll}
\hline Species & $\begin{array}{l}\text { Coverage } \\
(\%)\end{array}$ & Species & $\begin{array}{l}\text { Coverage } \\
(\%)\end{array}$ \\
\hline Kobresia persica & 53.69 & Ranunculus japonicus & 1.33 \\
Kobresia littledalei & 48.71 & Potentilla saundersiana & 1.18 \\
Kobresia humilis & 35.40 & Juncus effusus & 1.07 \\
Carex moorcroftii & 17.31 & Poa annua & 0.93 \\
Oxytropis bicolor & 10.58 & Festuca ovina & 0.91 \\
Primula malacoides & 9.67 & Artemisia comaiensis & 0.89 \\
Polygonum macrophyllum & 5.51 & Sium suave & 0.84 \\
Blysmus compressus & 5.44 & Eritrichium canum & 0.47 \\
Saussurea japonica & 5.33 & Rehmannia glutinosa & 0.27 \\
Aster tataricus & 5.11 & Geranium wilfordii & 0.24 \\
Polygonum fertile & 4.31 & Androsace umbellata & 0.22 \\
Astragalus arnoldii & 3.13 & Potentilla anserina & 0.22 \\
Gentiana scabra & 2.98 & Potentilla acaulis & 0.20 \\
Apocynum venetum & 2.76 & Hedinia tibetica & 0.18 \\
Stellaria media & 2.42 & Sonchus oleraceus & 0.09 \\
Triglochin palustre & 2.33 & Lagotis brachystachya & 0.04 \\
Leontopodium leontopodioides & 1.38 & Thalictrum squarrosum & 0.04 \\
\hline
\end{tabular}

In this research, some relationships between vegetation factors and soil erosion have been determined. However, the depth mechanism behind these relationships has not yet been revealed. Further research is still needed in the future. First, plant functional traits should be considered in further research. To date, there are considerable publications describing the relationship between soil erosion and plant functional traits. However, the seasonal factor, as an important effect on plant traits, has been poorly studied to date. Thus, it is necessary to study the relationship between plant functional traits and erosion with incorporating the seasonal factor into further research. Second, models of plant functional traits and erosion should be built. Currently, many studies focused on the models of plant functional traits and erosion at plant scale, while little has been done at the community scale. Additionally, the expression of plant functional traits at the community scale is the key to build the model.

\section{Conclusions}

After conducting a study in the Three-River Headwater region of China, an increase in plants distributed in an aggregation pattern, the soil ${ }^{137}$ Cs inventory, followed with soil particles, was increasingly intercepted by the developed vegetation patches. Such conditions result in more developed vegetation patches that can support a larger VC and greater plant diversity. Although there is a positive correlation between plant diversity and VC, no relationship is found between plant diversity and the soil ${ }^{137} \mathrm{Cs}$ inventory. The relationship between the amount of soil erosion (the soil ${ }^{137} \mathrm{Cs}$ inventory) and plant diversity is modulated by the vegetation pattern. When plants distribute in a relatively homogeneous pattern, with increasing plant diversity, VC decreases, leading to an increase in soil erosion. When plants distribute adhering to both a homogenous and a heterogeneous pattern, no relationship is found between plant diversity and soil erosion. With a heterogeneous plant distribution, VC increases with plant diversity; in addition, soil erosion is inhibited under these conditions.

\section{Acknowledgments}

We thank two anonymous reviewers for their helpful comments. This research was supported by the National Natural Science Foundation of China (No. 41230745).

\section{References}

Anderson, P.M.L., Hoffman, M.T., 2011. Grazing response in the vegetation communities of the Kamiesberg, South Africa: adopting a plant functional type approach. J. Arid Environ. 75 (3), 255-264.

Anthwal, N., Chai, Y., Tucker, A.S., 2008. The role of transforming growth factor-beta signalling in the patterning of the proximal processes of the murine dentary. Dev. Dyn. 237 (6), 1604-1613.

Bautista, S., Mayor, Á.G., Bourakhouadar, J., Bellot, J., 2007. Plant spatial pattern predicts hillslope runoff and erosion in a semiarid Mediterranean landscape. Ecosystems 10 (6), 987-998.

Boardman, J., 2006. Soil erosion science: reflections on the limitations of current approaches. Catena 68 (2-3), 73-86.

Boix-Fayos, C., et al., 2007. Causes and underlying processes of measurement variability in field erosion plots in Mediterranean conditions. Earth Surf. Process. Landf. 32 (1), 85-101.

Burylo, M., Rey, F., Bochet, E., Dutoit, T., 2012. Plant functional traits and species ability for sediment retention during concentrated flow erosion. Plant Soil 353 (1-2), 135-144.

Cadotte, M.W., Carscadden, K., Mirotchnick, N., 2011. Beyond species: functional diversity and the maintenance of ecological processes and services. J. Appl. Ecol. 48 (5) 1079-1087.

Cerda, A., 1997. The effect of patchy distribution of Stipa tenacissima L. on runoff and erosion. J. Arid Environ. 36, 37-51.

Fassnacht, F.E., Li, L., Fritz, A., 2015. Mapping degraded grassland on the Eastern Tibetan Plateau with multi-temporal Landsat 8 data - where do the severely degraded areas occur? Int. J. Appl. Earth Obs. Geoinf. 42, 115-127.

Fu, B.J., et al., 2009. The effects of land-use combinations on soil erosion: a case study in the Loess Plateau of China. Prog. Phys. Geogr. 33 (6), 793-804

Greene, R.S.B., Kinnell, P.I.A., Wood, J.T., 1994. Role of plant cover and stock trampling on runoff and soil erosion from semi-arid wooded rangelands. Aust. J. Soil Res. 32, 953-973.

Harris, R.B., 2010. Rangeland degradation on the Qinghai-Tibetan plateau: a review of the evidence of its magnitude and causes. J. Arid Environ. 74 (1), 1-12. 
Hou, J., Fu, B., Wang, S., Zhu, H., 2014. Comprehensive analysis of relationship between vegetation attributes and soil erosion on hillslopes in the Loess Plateau of China. Environ. Earth Sci. 72 (5), 1721-1731.

Lehnert, L.W., Meyer, H., Meyer, N., Reudenbach, C., Bendix, J., 2014. A hyperspectral indicator system for rangeland degradation on the Tibetan Plateau: a case study towards spaceborne monitoring. Ecol. Indic. 39, 54-64.

Li, S., Li, D., Zhao, P., Zhang, G., 2009. The climatic characteristics of vapor transportation in rainy season of the origin area of three rivers in Qinhai-Xizang Plateau. Acta Meteorol. Sin. 67 (4), 591-598.

Liu, W., Guo, Q.H., Wang, Y.X., 2008. Temporal-spatial climate change in the last 35 years in Tibet and its geo-environmental consequences. Environ. Geol. 54 (8), 1747-1754.

Ludwig, J.A., Bartley, R., Hawdon, A.A., Abott, B.N., McJannet, D., 2007. Patch configuration non-linearly affects sediment loss across scales in a grazed catchment in north-east Australia. Ecosystems 10 (5), 839-845.

Marques, M.J., Bienes, R., Jimenez, L., Perez-Rodriguez, R., 2007. Effect of vegetal cover on runoff and soil erosion under light intensity events. Rainfall simulation over USLE plots. Sci. Total Environ. 378 (1-2), 161-165.

Marston, R.B., 1952. General cover requirements for summerstorm runoff control on Aspen sites in Northern Utah. J. For. 50, 303-307.

Martin, C., Pohl, M., Alewell, C., Körner, C., Rixen, C., 2010. Interrill erosion at disturbed alpine sites: effects of plant functional diversity and vegetation cover. Basic Appl. Ecol. 11 (7), 619-626.

Navarro, T., Alados, C.L., Cabezudo, B., 2006. Changes in plant functional types in response to goat and sheep grazing in two semi-arid shrublands of SE Spain. J. Arid Environ. 64 (2), 298-322.

Parsons, A.J., Foster, I.D.L., 2011. What can we learn about soil erosion from the use of ${ }^{137}$ Cs? Earth Sci. Rev. 108 (1-2), 101-113.
Pohl, M., Alig, D., Korner, C., Rixen, C., 2009. Higher plant diversity enhances soil stability in disturbed alpine ecosystems. Plant Soil 324 (1-2), 91-102.

Porto, P., Walling, D.E., Ferro, V., 2001. Validating the use of caesium-137 measurements to estimate soil erosion rates in a small drainage basin in Calabria, Southern Italy. J. Hydrol. 248, 93-108.

Riis, T., Hawes, I., 2002. Relationships between water level fluctuations and vegetation diversity in shallow water of New Zealand lakes. Aquat. Bot. 74 (2), 133-148.

Saco, P.M., Willgoose, G.R., Hancock, G.R., 2007. Eco-geomorphology of banded vegetation patterns in arid and semi-arid regions. Hydrol. Earth Syst. Sci. 11, 1717-1730.

Shao, Q., Xiao, T., Liu, J., Qi, Y., 2011. Soil erosion rates and characteristics of typical alpine meadow using ${ }^{137} \mathrm{Cs}$ technique in Qinghai-Tibet Plateau. Chin. Sci. Bull. 56 (13), 1019-1025.

Turnbull, L., Wainwright, J., Brazier, R.E., 2008. A conceptual framework for understanding semi-arid land degradation: ecohydrological interactions across multiple-space and time scales. Ecohydrology 1 (1), 23-34.

Yi, H.S., et al., 2013. The early Jurassic oil shales in the Qiangtang Basin, northern Tibet: biomarkers and Toarcian Oceanic Anoxic Events. Oil Shale 30 (3), 441-455.

Zhang, X.B., Zhang, Y.Y., Wen, A.B., Feng, M.Y., 2003. Assessment of soil losses on cultivated land by using the ${ }^{137}$ Cs technique in the Upper Yangtze River Basin of China. Soil Tillage Res. 69, 99-106.

Zhou, P., Luukkanen, O., Tokola, T., Nieminen, J., 2008. Effect of vegetation cover on soil erosion in a mountainous watershed. Catena 75 (3), 319-325.

Zhu, H., et al., 2015. Reducing soil erosion by improving community functional diversity in semi-arid grasslands. J. Appl. Ecol. 52 (4), 1063-1072. 